\title{
ALÉM DA DIMENSÃO INSTITUCIONAL, OU MELHOR, O PAPEL DO INDIVÍDUO NA DIATRIBE ENTRE A LAICIDADE E A LIBERDADE RELIGIOSA ${ }^{1}$
}

Roberto Cipriani ${ }^{2}$

\section{PREMISSA}

No texto de Diotallevi, parece ser inteiramente ausente a dimensão subjetiva das escolhas que cada ator social realiza no curso de sua existência e que prescindem, na medida do possível, de quadros institucionais de referência. Na verdade, nem tudo é tratado no nível estrutural. E, mesmo em um regime altamente constritivo, o indivíduo sozinho será capaz de exprimir, de algum modo, a sua liberdade religiosa, a sua taxa de laicidade.

Contudo, mesmo sem compartilhar os excessos da rational choice (Coleman, 1990), é comprovado que, de tempos em tempos, toma-se uma decisão - e, desta vez, é sério - de acordo com o contexto, a situação do momento, as perspectivas futuras, as preferências de base. Para não falar dos fatores emocionais, afetivos, autorreverenciais e autorreferenciais que fazem prevalecer aquilo que parece irracional em relação ao que pareceria mais racional.

As diferenças funcionais, aliás, não passam somente por meio dos limites hard da sociedade, mas atingem também o nível soft, extremamente maleável, flexível, talvez até baumanianamente "líquido", (Bauman, 2000) da vontade individual.

No entanto, é necessário partir de um fato que não é facilmente questionável: lá onde uma forma de religião, em sentido lato, está presente e operante, ela possui seu capital (de vários tipos: cultural, econômico, social,

1 Tradução: Jane Diogo Trein. Revisão: Cláudia Mendonça Scheeren.

2 Professor da Universidade de Roma TRE. Contato: roberto.cipriani@tlc.uniroma3.it

Debates do NER, Porto Alegre, ano i6, N. 27, P. 97-III, JAN./Jun. 2015 
relacional, entre outros), que permite interagir no campo da comparação entre público e privado, de igual para igual ou quase, com outras formas sociais (estatais, políticas, econômicas, sindicais, corporativas etc.).

Há de se considerar também que os três (ou principalmente dois) casos tomados para serem examinados não só apresentam diferenças substanciais entre eles (que realmente Diotallevi reconhece), mas contêm, todavia, dentro deles posições e perspectivas que não são facilmente homogeneizáveis em um único modelo nacional ou estatal ou federal. Mesmo sem examinar a fratalização dos Estados Unidos, o exemplo britânico do, assim chamado, Reino Unido apresenta problemas que não são facilmente solucionáveis com um referendum, como aquele mais recente acerca da independência da Escócia, que expôs todas as sequelas e insatisfações profundamente enraizadas em uma parte da população que permanece consideravelmente desiludida com o resultado em favor da manutenção do status quo.

\section{RELIGIÃO E POLÍTICA}

Em primeiro lugar, é necessário se perguntar se realmente decaiu a influência da religião na política em geral. Estamos falando de países que sempre tiveram ligação com a religião católica, anglicana, protestante ou cristã que fosse, para não falar de outras rupturas e vicissitudes que de vez em quando atravessam o mundo transalpino, o contexto norte-americano e o albiônico.

Entretanto, lá onde o secularismo parece então ter se estabelecido também no plano jurídico (obviamente a referência é a França e a sua lei de 1905), a realidade, na verdade, apresenta diversas fendas e a laicidade estabelecida... arruina-se! Em suma, mesmo em situações extremas, registram-se, no entanto, formas de acomodação, compromissos, acordos substanciais aos quais se seguem conflitos e confrontos de fachada e pro forma.

Radicalismo e moderantismo, sem dúvida, incluem-se entre as modalidades habituais dos regimes e dos comportamentos políticos. Para dizer a verdade, não faltam casos em que o radicalismo se modera e se torna realista e o moderan-

Debates do NER, Porto Alegre, ANo i6, N. 27, P. 97-III, JAn./Jun. 2015 
tismo, de sua parte, se radicaliza. Entre o fundamentalismo e o possibilismo não existe, realmente, de fato um hiato claro, mas uma certa dose de continuidade, mais ou menos marcada pelas contingências e pelas conveniências.

O sociólogo perspicaz bem sabe que, especialmente na política, o dito pode ser desmentido facilmente pelos fatos. Basta uma mudança de regime, o advento de um líder diferente daquele que o precedeu; a necessidade de não estimular as contraposições por razões instrumentais em vista de ganhos posteriores de créditos e consensos. E, portanto, eis que a laicidade oficializada pelo Estado é repudiada pelos fatos cotidianos.

Hoje mesmo, enquanto estou escrevendo estas reflexões, presenciei cenas contraditórias e ouvi afirmações conflitantes por parte de um mesmo sujeito que não só deve ser considerado único, mas também peculiarmente representativo de uma situação muito difundida. E aqui estão os fatos.

Estava prestes a começar uma manifestação não só de cunho religioso, mas étnico-nacionalista ao mesmo tempo. Uma entrevistadora aproximou-se de um alto oficial do exército que estava fardado, presente no local, porém em uma posição mais ou menos pessoal (mas, então, por que de farda?). Antes de dar a entrevista, o militar começou dizendo que não tencionava, de modo algum, falar de política. E, portanto, o conteúdo das perguntas e das respostas permaneceu em um nível totalmente religioso e cultural no sentido mais amplo. Entretanto, deve-se notar que aquele representante do Estado, com a sua presença na cerimônia religiosa, já estava cumprindo publicamente um ato de grande visibilidade e significado sociopolítico. Não só. Pouco depois, posicionou-se na primeira fileira, com todos os seus galôes dourados e um quepe de alto posto para carregar uma faixa de evidente caráter religioso e político, enquanto era apresentada, simultaneamente, a imagem sacra venerada naquela ocasião, junto com os símbolos oficiais de dois Estados-Nação. Em seguida, um sacerdote começou o rito com uma oração, também recitada fervorosamente pelo coronel. Poucos minutos depois, foram executados dois hinos nacionais: um do país de origem dos imigrantes, que se reuniram para a festa de seu santo padroeiro, e o outro do país anfitrião. Em ambos os casos, obviamente, com um equilibrismo 
extraordinário de gestos e movimentos da cabeça, do rosto e das mãos, o alto oficial conseguiu, ao mesmo tempo, cantar em voz alta as palavras de seu hino nacional, saudar militarmente com a mão direita apoiada no quepe e a segurar firmemente o cartaz com o título e os símbolos da manifestação política e religiosa. Portanto, esta foi realmente uma extraordinária metáfora das dinâmicas habituais que se interpõem entre a Igreja e o Estado, entre laicidade e religiosidade, entre político e religioso.

De cunho diferente, mas, no final das contas, com um resultado final bastante similar, é uma outra experiência empírica no campo da pesquisa ligada a manifestaçôes de religiosidade popular. Refiro-me à Polônia e à peregrinação masculina (Cipriani, 2014) ao santuário da Virgem de Piekary na década de 80 , no momento em que o movimento Solidarność era considerado fora da lei pelo governo filocomunista. Então, a única possibilidade de se fazer presente era a de participar com as suas bandeiras e suas faixas nas procissões e nos ritos populares religiosos. Por outro lado, a hierarquia eclesiástica escolhia o direito oferecido pelo encontro de dezenas de milhares de pessoas para mover pesadas críticas do púlpito aos governantes. Culpados de um grave desastre ambiental, devido à presença, a céu aberto, de todos os resíduos do trabalho nas minas de carvão. Para não mencionar, então, o estreito entrelaçamento entre política e religião personificado pela mesma figura de um Papa polonês protagonista de uma influência importante nos acontecimentos sociopolíticos de seu país. A imagem de João Paulo II, colocada bem à vista, sobressaía-se solenemente no lugar do rito em Piekary.

Mas a casuística não para por aqui. $\mathrm{O}$ que dizer então do peso da religião em uma realidade social como aquela da Argentina? Quando Jorge Mario Bergoglio era cardeal e ordinário diocesano de Buenos Aires, intervinha abertamente nas questóes políticas, na presença do próprio líder do governo, Nestor Kirchner, que que vinha sendo duramente criticado por sua gestão nos assuntos públicos. Atualmente, o mesmo Bergoglio, em seu novo papel de Papa, presta bem mais atenção ao intervir. No entanto, é a mesma parte do governo a ter mudado de atitude: não mais um distanciamento, mas contínuas tentativas de reaproximação, também física, uma vez que a presi-

Debates do NER, Porto Alegre, ANo i6, N. 27, P. 97-III, JAN./Jun. 2015 
dente, Cristina Kirchner, sucessora de seu marido, repetidamente viajou a Roma, no Vaticano, para encontrar o seu adversário ideológico de outrora.

Por outro lado, há de se considerar que também a liberdade religiosa, proclamada e conclamada nos textos legislativos de algumas nações, na verdade, é, então, negada, sobretudo lá onde algumas expressões confessionais são favorecidas e, outras, ao contrário, são marginalizadas, financiadas por uns e penalizadas por outros. Isso acontece, com maior frequência, onde uma determinada religião é dominante ou também é reconhecida como a religião oficial do Estado, razão pela qual a codificada tomada de posição jurídica de religious freedom é contradita pelas evidências dos fatos, que veem um exercício diferenciado de liberdade, estratificado segundo privilégios concedidos ou negados, de acordo com as autorizaçóes e proibições, segundo rigorismos e laxismos, de tempos em tempos implementados com base no indivíduo religioso receptor.

Em suma, no Estado pressupostamente laico como aquele em que está em vigor formalmente a liberdade religiosa, verificam-se inúmeras vezes desvios, remanejamentos, adaptaçôes, que na verdade, repudiam - é realmente o caso de dizê-lo com este verbo - os princípios inspiradores. A isso, acrescente-se que dificilmente uma normativa, escrita ou pragmática, conseguirá tirar dos indivíduos as suas prerrogativas de escolha final, de decisão operativa. Por isso, de um ponto de vista sociológico, convém, ainda mais, investigar o terreno das situaçôes concretas.

\section{DIOTALLEVI DEFENDE...}

Convém, antes de acrescentar outras observações mais ou menos críticas, colocar em foco com uma certa clareza expositiva e precisão terminológica o que é defendido por Diotallevi, o qual parte da constatação de que o "separatismo moderado" entre Estado e igreja (ou religião, principalmente cristã, nos casos da França, dos Estados Unidos e da Grã-Bretanha) seria dominante. Em suma, prevaleceria a tendência à adaptação, ao compromisso, às soluções intermediárias. Ao contrário, a contraposição férrea, absoluta e

Debates do NER, Porto Alegre, Ano i6, N. 27, P. 97-III, JAN./Jun. 2015 
rígida do "separatismo radical" não pareceria ter muito espaço. E também, nas formas de "separatismo moderado", seriam encontradas facilmente muitas diferenças tipicamente funcionais, que Diotallevi procura colocar em evidência, amparando-se nos pensamentos de Niklas Luhmann (1984; 1990) que via a sociedade como caracterizada por uma substancial diferenciação de acordo com funções.

Entre outras coisas, os modelos do secularismo, assim como os do separatismo, também são "múltiplos", segundo a perspectiva sugerida por Alfred Stepan (2011), usada como suporte por Diotallevi. E não é por acaso que a própria secularização foi também definida como processo de diferenciação funcional dentro da religião ou da Igreja (ou das Igrejas cristãs em sentido lato).

Os fatores em jogo são, obviamente, de natureza política e religiosa, mas Diotallevi leva em consideração também os de matriz jurídica, essencialmente em conexão com a questão dos direitos; este último tema ainda referente à derivação luhmanniana (Luhmann, 1984; 1990).

Via de regra, sustenta-se ter em ação uma linha de tendência voltada à cooperação apesar do "separatismo radical" da França e Estados Unidos. Isto também confirmaria "a retomada da influência da religião na política" apresentada por Casanova (1994).

Mas a este respeito vale a pena se perguntar quando, em quais circunstâncias, em quais contextos nacionais e internacionais tal influxo tenha decaído e por quanto tempo. Aqui, porém, não se está analisando a contribuição do sociólogo hispano-norte-americano, que será melhor reexaminado em um outro momento.

Um par fundamental de conceitos no discurso de Diotallevi é o constituído pela Laicidade (laïcité) e liberdade religiosa (religious freedom). A primeira é contextualizada na França, a segunda, mais nos Estados Unidos. Mas não é só esta a diferença dos dois separatismos considerados radicais. Será particularmente a referência aos aspectos jurídicos que fixará um dado divisor de águas.

Um ponto estratégico é a tomada em consideração de Diotallevi, por razões expositivas e argumentativas, da ideia de Madeley (2003) de um 
"desmantelamento de todas as formas de religião de Estado" (antidisestablishmentarianism), datável ao vicênio entre 1980 e 2000, considerando que, anteriormente, entre 1900 e 1970 teria ocorrido exatamente o contrário, isto é, uma separação clara entre a esfera política e a esfera religiosa, a partir da lei francesa de 1905 sobre a laicidade do Estado.

Contudo, torna-se difícil aceitar essas periodizações tão precisas nos anos de início e fim quanto vagas nos conteúdos de referência. No entanto, o intervalo de tempo entre 1971 e 1979 continua a agir como um amortecedor entre as duas fases alternativas, sem qualquer caracterização. (Um período de transição? Uma fase de incerteza? Um longo momento de reflexão? Uma neutralidade casual ou intencional?). Aqui, a crítica não é dirigida a Diotallevi, mas aos autores que amam deixar de lado as fases históricas e os fenômenos que normalmente não apresentam soluções evidentes de continuidade.

Entretanto, afirma-se que, superada a concepção de uma religião de Estado, ou de um Estado confessional, mas também a de um Estado completamente separado das questóes religiosas, o dado de fato assim chamado de "novo", seria o envolvimento estatal, governativo, nas religious issues, com modalidades muito diferentes entre si, especialmente nos dois (ou três casos) objeto de estudo por parte de Luca Diotallevi. A este respeito, ele poderia trazer algum elemento posterior à discussão e referência ao caso mexicano, em que efetivamente, e mais que em outro lugar, vige a proibição de "[...] usar [...] publicamente roupas ou sinais que expressem uma entidade religiosa" (Diotallevi, 2015, p. 22).

Agora, porém, convém examinar a pedra fundamental da abordagem: duas cláusulas da primeira emenda à Constituição dos EUA dão lugar ao princípio de religious freedom que marca a distinção entre o modelo dos Estados Unidos e da França. Oportunamente, reporta-se a Jepperson (2002) para avaliar se uma sociedade é mais corporativa (para defesa dos direitos de grupos específicos) ou associativa (voltada a defender os direitos de todos) e também se é gerida de modo mais ou menos institucionalizado ou mais ou menos invasivo dos direitos individuais. A esse respeito, Diotallevi remete-se justamente a Silvio Ferrari (2012), mas negligencia outra contribuição fundamental como a de Francesco Margiotta Broglio (2011).

Debates do NER, Porto Alegre, Ano i6, N. 27, P. 97-III, JAN./Jun. 2015 
Mas passemos ao essencial: tudo baseia-se no fato de que, nos Estados Unidos, a liberdade religiosa vem em primeiro lugar, antes mesmo da liberdade de consciência; e, na França, ao invés, é a própria liberdade de consciência que permite e garante a liberdade religiosa. Enfim, entre os dois separatismos, corre um sulco bem profundo, que diz respeito aos fatores-chave da questão, mas que sobretudo não pode evidenciar a centralidade do papel do indivíduo nas suas escolhas de fundo. Na prática, é o sujeito social que decide o que fazer, mesmo prescindindo das declaraçôes de princípios, das leis em vigor, da primazia da religião e/ou consciência. Ele tem os seus direitos e os usa na íntegra, só com a prudência de não incorrer em eventuais sanções estatais. Resumindo, a autonomia subjetiva, de qualquer maneira, reemerge sempre, também em uma condição de absoluta negação da liberdade dos direitos dos cidadãos individualmente.

Todavia, o Estado continua a estar muito presente no modelo de regime fundado na laïcité, em que ele reserva para si mesmo a gestão da presença da religião no espaço público (enquanto o cidadão pode expressar-se religiosamente em particular). No contexto de religious freedom, os indivíduos, ao contrário, teriam o direito de participar de forma pública nas suas atividades de natureza religiosa e desse modo impediriam, de fato, o Estado de estender o próprio poder até colonizar todo o espaço público.

No gráfico ilustrativo no final, que poderia ser mais bem elaborado, Diotallevi destaca a separação entre público e privado como pertencente à laïcité, razão pela qual a religião permaneceria confinada no privado. A separação de tipo religious freedom, ao contrário, diz respeito, precisamente, ao espaço público no qual os cidadãos manifestam abertamente as suas crenças e participam de suas cerimônias, mas o Estado não intervém e, portanto, não pode manifestar a sua influência. $\mathrm{Na}$ prática, para as questôes religiosas, o espaço público (homogêneo, indiferenciado) do modelo francês é atribuído ao Estado; no norte -americano, às confissões religiosas que fazem algo fortemente diferenciado e livre de condicionamentos externos do Estado (ou de outras instituiçóes).

A contribuição de Diotallevi prossegue, então, com uma retomada do tema luhmanniano dos direitos, em particular do Grundrecht como 
"instituição" capaz de combinar o direito de liberdade com o direito de igualdade (sobre isso, seja dito incidentalmente, jogam-se as partidas por parte das religiōes minoritárias que aspiram a obter uma legitimação por parte do Estado com a finalidade de poder praticar abertamente os seus cultos, com o mesmo título que a religião do Estado ou reconhecida pelo Estado ou de alguma forma dominante em um dado contexto nacional ou territorial). Enfim, a liberdade e a igualdade são critérios fundamentais do Grundrecht, isto é, da "instituição" que garante a diferenciação e a liberdade religiosa, favorecendo o respeito político do religioso, isto é, da liberdade individual.

Em segundo lugar, Diotallevi observou que a moderação, ou melhor, a manutenção de um equilíbrio entre direito de liberdade e direito de igualdade impede a vinda de uma supremacia do social sobre o pessoal (ou ainda do contrário). A justa combinação das duas cláusulas (da liberdade ou do disestablishment e da igualdade, ou seja, do free exercise) dá lugar a uma liberdade religiosa nos Estados Unidos bem diferente da de outros contextos socioterritoriais.

E, por fim, o luhmanniano "acoplamento estrutural" entre política e religião, como dois subsistemas do sistema social do qual derivam os direitos fundamentais, permite justamente a liberdade religiosa como um direito fundamental. Deve acrescentar-se, no entanto, que o subsistema político também interage com o sistema judiciário. De fato, o religious freedom norte-americano baseia-se na triangulação entre política, religião e direito.

Exatamente o "acoplamento estrutural" diferente faz divergir o separatismo radical da federação norte-americana do da francesa. Com efeito, é impensável que o modelo francês seja aplicado nos EUA. Isso se deve ao fato de que o religioso e o político dos dois contextos contêm elementos muito diferentes entre si. A diversificação diz respeito ao próprio subsistema jurídico, que é common law nos Estados Unidos (e na Grã-Bretanha), com base nas práticas de regulamentação que de tempos em tempos consolida-se, mas de civil law e de Estado de direito na França (ou Rechtstaat na Alemanha), com leis homogêneas escritas e não fácil e imediatamente modificáveis. 
Por outro lado, historicamente, a lä̈cité tem como matriz a paz de Vestfália (1648), com o início da secularização que legitima o domínio estatal, enquanto o religious freedom não tem um antecedente histórico correspondente e, assim, se desenvolve no âmbito de outros horizontes.

Em uma sociedade funcionalmente muito diferenciada, caso se registre um retorno do peso da religião na política, isso não quer dizer que se está diante de um processo de de-diferenciação. Do mesmo modo, não é possível entender de forma inequívoca o que acontece em uma sociedade que é pouco diferenciada, uma vez que o político dominou: em tal caso, a retomada da influência religiosa na política não pode ter um significado claro.

Mas, os dois separatismos radicais e secularismos radicais, norte-americano e francês, têm orientações diferentes também em relação às Igrejas. Nos Estados Unidos (modelo da sociedade sem Estado), visa-se à manutenção da diferenciação funcional da sociedade, na França (modelo da sociedade de Estado), essa diferenciação é questionada.

Além disso, nos EUA, assiste-se a uma ausência da tentativa de governar e organizar a sociedade, em vez disso, na França, existe uma diferente gestão da diferenciação entre política e religião, que envolve uma ligação mais estreita entre o poder dominante do Estado e o poder judiciário, bem como um controle direto do Estado sobre o espaço público.

Apesar de tudo, no entanto, a cooperação entre política e religião coexiste em ambas as realidades sociais em questão, segundo as formas de separatismo e secularismo, ambos moderados, mas também muito diferenciados. Assim, nos Estados Unidos, a cooperação apresenta-se também como competição, concorrência, entre Estado e igrejas, o que não está no regime da lä̈cité, no qual o Estado prevalece e de fato administra a colaboração entre política e religião.

Deve-se notar que muito depende da relação (mais autônoma ou menos autônoma) do subsistema judiciário em relação ao político. O nível de tal autonomia deveria ser medido mais adequadamente no âmbito do grupo supostamente mais numeroso, representado pelo separatismo moderado.

Debates do NER, Porto Alegre, ANo i6, N. 27, P. 97-III, JAN./Jun. 2015 
Finalmente, deve-se ter em mente que o religious freedom norte-americano possui origens britânicas e é diferente daquele do norte europeu luterano e dos Estados que legitimam a religião católica ou outra religião cristã como religião de Estado.

Por outro lado, o modelo de laicidade à francesa não pode permanecer como único ponto de referência (Blancarte, 2013). A própria Europa tem situações muito variadas não reduzíveis à unidade.

Em última análise, para Diotallevi, a laïcité não deveria mais ter muita relevância, levando em conta as inúmeras e diversas experiências a seu respeito. Em particular, o dado sociológico que dá suporte à tese diotalleviana seria de uma presença majoritária do "secularismo moderado" que atestaria entre $70 \%$ e $90 \%$ (de qual universo estatístico? Com quais indicadores? Revelado por quem, onde, quando?).

\section{...MAS NÃO SE PODE ESQUECER QUE...}

As reflexões teóricas de Diotallevi não são banais, mas deveriam ser reforçadas mediante dados empíricos ou, pelo menos, colocados em comparação com resultados de pesquisas de campo.

Além disso, deve ser apreciado o esforço, junto com a honestidade intelectual, de querer atualizar um debate sobre o tema da laicidade que ficou demasiado ancorado à diatribe de matriz francesa, claramente datada em 2005, ano em que se comemorou o centenário da lei sobre a laicidade do Estado, aprovada em nove de dezembro de 1905 (já em sete de julho de 1904, os religiosos tinham sido excluídos do ensino). Certamente, o primeiro artigo da Lei de 1905 indicava a primazia da liberdade de consciência. Portanto, é a partir daquela primeira orientação dada pela lei que deriva a primazia da consciência no que diz respeito à religião, e, consequentemente, o direito de liberdade de consciência em relação ao direito de liberdade religiosa. 
Ao mesmo tempo, não se pode, todavia, deixar de salientar que, ao contrário do que foi afirmado no segundo artigo da referida lei ("a República não reconhece nem paga e nem subsidia qualquer culto"), a verificação empírica a respeito disso prova exatamente o contrário, especialmente na França, na Alsácia e na Lorena. Para não mencionar a maciça intervenção do Estado francês para a preservação do patrimônio histórico e cultural da Igreja Católica: trata-se de quantias imensas e quase incontroláveis, que nem os mais atualizados especialistas do setor são capazes de quantificar. Pode-se também supor que o montante total seja superior ao que o Estado italiano paga à Igreja Católica de acordo com a declaração de impostos dos cidadãos que optam em favor da atribuição de oito partes de mil de seus impostos em favor da religião mais difundida.

Algumas observações finais. Fala-se de uma crítica de Moodod (2012) a Bhargava, mas nada é dito sobre este autor e sua posição no debate em curso. O tema da neutralidade em matéria de religião só é mencionado com duas rápidas referências bibliográficas a Ahdar e Leigh (2005) e a Monsma (2000), contudo, o assunto não é secundário pelas problemáticas que levanta. A colocação entre parênteses da situação da Grã-Bretanha e o contemporâneo privilégio das questôes imersas na França e nos Estados Unidos talvez impeçam uma maior riqueza para o debate em curso. A quadripartição das combinações entre o nível institucional alto e baixo da public agency e da sociedade corporativa ou associativa se desenvolvia de um modo mais explícito, talvez até didático, em benefício do leitor. Permanece, entretanto, vago o conceito de Grundrecht como instituição, mesmo para a pouco ágil e difusa familiaridade com o pensamento de Luhmann. A propósito deste último, parece um pouco abstrata a ideia de que o subsistema político se defenda de outros subsistemas e deixe o espaço de ação fora dele: na realidade dos fatos, as dinâmicas são bastante complicadas e não facilmente classificáveis, especialmente na visão externa em relação ao subsistema político. A referência a Simmel (1890) é relevante na nota dez, no rodapé, deixando na verdade indefinidos o conceito e o processo 
de "individualização" junto ao da diferenciação. O mesmo aplica-se aos conceitos de state society e de stateless society. Por fim, um olhar específico para a Europa como uma comunidade sociopolítica e econômico-cultural poderia ser apropriado. Uma bibliografia atualizada e abundante torna-se, certamente, muito útil.

$\mathrm{O}$ modo de proceder de Diotallevi às vezes cria problemas, porque faz alusão e sintetiza, toma como certo e frequentemente dá saltos de lógica, que interrompem a continuidade do raciocínio. Eu não nego que a leitura foi cansativa, mas, no final, houve a compreensão do texto. ${ }^{3}$

3 Dedico, grato, este texto a Massimo Rosati, que pouco antes de nos deixar, me repreendeu por ser muito crítico com Luca Diotallevi.)

Debates do NER, Porto Alegre, ano i6, N. 27, P. 97-III, JAN./Jun. 2015 


\section{REFERENCIAS}

AHDAR, Rex; LEIGH, Ian. Religious Freedom in the Liberal State. Oxford: Oxford University Press, 2005.

BAUMAN, Zygmunt. Liquid Modernity. Cambridge, UK: Polity Press, 2000.

BLANCARTE, Roberto. Las leyes de reforma y el estado laico: importancia histórica y validez contemporánea. México, D.F.: El Colegio de México; Universidad Nacional Autónoma de México, 2013.

BROGLIO, Francesco Margiotta. Religione, diritto e cultura politica nell'Italia del Novecento. Bologna: Il Mulino, 2011.

CASANOVA, José. Public Religions in the Modern World. Chicago: University of Chicago Press, 1994.

CIPRIANI, Roberto. Un pellegrinaggio al maschile: il caso di Piekary. In: PRUFER, Paweł; SLOWINSKI, Przemysław (Ed.). Relacja, Komplementarność, integracja wtoskie i polskie osobliwości, Państwowa Wyższa Szkota Zawodowa im. Jakuba z Paradyża w Gorzowie Wielkopolski, 2014.

COLEMAN, James. Foundations of Social Theory. Cambrige, MA: Harvard University Press, 1990.

FERRARI, Silvio. Law and Religion in a Secular World: a European Perspective. Ecclesiastical Law Journal, Cambridge, UK, n. 14, v. 3, p. 355-370, 2012.

JEPPERSON, Ronald. Political Modernities: Disentangling two Underlying Dimensions of Institutional Differentiation. Sociological Theory, n. 20, v. 1, p. 61-85, 2002.

LUHMANN, Niklas. Religious Dogmatics and the Evolution of Societies. New York: Mellen, 1984. . La differenziazione del diritto. Bologna: Il Mulino, 1990.

Debates do NER, Porto Alegre, ANo i6, N. 27, P. 97-III, JAN./Jun. 2015 
MADELEY, John. European Liberal Democracies and the Principle of State Religious Neutrality. In: Church and State in Contemporary Europe: The Chimera of Neutrality. London: Frank Cass, 2003. p. 1-22.

MODOOD, Tariq. Moderate Secularism, Religion as Identity and Respect for Religion. In: REED, Esther; DUMPER, Michael. Civil Liberties, National Security and Prospects for Consensus. Cambridge, UK: Cambridge University Press, 2012. p. 62-80.

MONSMA, Stephen. Substantive Neutrality as a Basis for Free Exercise: No Establishment Common Ground. Journal of Church \& State, Oxford, n. 42, v. 1, p. 13-36, 2000.

SIMMEL, Georg. Über Soziale Differenzierung: Soziologische und psychologische Untersuchungen. Leipzig: Duncker \& Humblot, 1890.

STEPAN, Alfred. The Multiple Secularism of Modern Democratic and Non-Democratic Regimes. In: CALHOUN, Craig; JUERGENSMEYER, Mark; VAN ANTWERPEN, Jonathan. Rethinking Secularism. Oxford: Oxford University Press, 2011. p. 114-144.

Recebido em: 20/07/2014

Aprovado em: 05/082014 